\title{
Comparison of Growth in Children with Cyanotic and Acyanotic Congenital Heart Disease in a Tertiary Care Hospital
}

\author{
F CHOWDHURY ${ }^{\mathrm{a}}$, M HOQUE ${ }^{\mathrm{b}}, \mathrm{M} \mathrm{M} \mathrm{ALI}^{\mathrm{c}}, \mathrm{M} \mathrm{A} \mathrm{HOSSAIN}^{\mathrm{d}}$
}

\begin{abstract}
Summary:
Background: Congenital heart disease (CHD) is the commonest of all congenital lesions and is the most common type of heart diseases among children. Anthropometric evaluation is very important for early recognition of growth failure in children with cyanotic and acyanotic congenital heart diseases.

Methods: This comparative cross sectional study was undertaken with the objective to compare the growth of children with cyanotic and acyanotic congenital heart disease using anthropometric measurement in Department of Paediatrics, Sylhet MAG Osmani Medical College Hospital from March, 2014 to September, 2014. Sixty children aged 6 months to 60 months with CHD, were included in this study, where 30 children with cyanotic and 30 children with acyanotic CHD, confirmed by Echocardiogram.
\end{abstract}

Results: All the children (100\%) with cyanotic congenital heart disease were underweight (Weight for age $Z$ score). Among them, $23.33 \%$ had moderate and $76.67 \%$ had severe underweight. In children with acyanotic congenital heart disease, 93.33\% had underweight. Among them, 20\% had moderate and $73.33 \%$ had severe underweight. The p-value was 0.35008. In cyanotic congenital heart disease, 96.67\%

Introduction:

Congenital heart diseases (CHD) are structural problems that arise from abnormal formation of the heart or major blood vessels. ${ }^{1}$ It is the commonest of

a. Dr. Fahmida Chowdhury, Registrar, Department of Paediatrics, Sylhet MA G Osmani Medical College, Sylhet

b. Dr. Mujibul Hoque, Department of Paediatrics, Sylhet M A G Osmani Medical College, Sylhet

c. Prof. Dr. Md. Manajjir Ali, Professor and Head, Department of Paediatrics, Sylhet M A G Osmani Medical College, Sylhet

d. Dr. Md. Anisul Hossain, Medical Officer, Goawainghat Upazila Health Complex, Gowainghat, Sylhet.

Address of Correspondence: Dr. Fahmida Chowdhury, Registrar, Department of Paediatrics, Sylhet MA G Osmani Medical College, Sylhet,

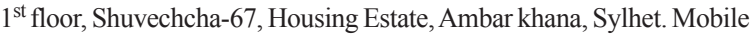
no.01717497104,e-mail:hi_fahmida@yahoo.com

Received: 23 Sept. 2017

Accepted: 20 Feb. 2018 children had stunting. Among them, 13.33\% had moderate and $83.33 \%$ had severe stunting. In acyanotic congenital heart disease, $43.33 \%$ children had stunting. Among them, 33.33\% had moderate and $10 \%$ had severe stunting. There was significant statistical deference in between the two groups, ( $p$ value was $<0.0001$ ). In cyanotic congenital heart disease, 43.33\% children had wasting. Among them, 30\% had moderate and $13.33 \%$ had severe wasting. In acyanotic congenital heart disease, 76.67\% children had wasting. Among them, 30\% had moderate and $46.67 \%$ had severe wasting. There was significant deference in the groups (p value was 0.0077).

Conclusion: Growth failure was common in children with both cyanotic and acyanotic congenital heart disease. There was no significant difference in weight for age $Z$ score (WAZ) of patients with cyanotic and acyanotic CHD but stunting was significantly higher in patients with cyanotic CHD and wasting was significantly higher in patients with acyanotic CHD.

Key words: Congenital heart disease (CHD), cyanotic congenital heart disease, acyanotic congenital heart disease, TOF (Tetralogy of Fallot), VSD (Ventricular septal defect), underweight, stunting, wasting, WAZ (Weight for Age Z score).

(J Bangladesh Coll Phys Surg 2018; 36: 64-69) DOI: http://dx.doi.org/10.3329/jbcps.v36i2.36068

all congenital lesions and is the most common type of heart diseases among children. ${ }^{2}$ The incidence of congenital heart disease is approximately 8 per 1000 live birth with a higher rate in stillbirth, spontaneous abortion and prematurity. And this incidence has remained constant worldwide. ${ }^{3} \mathrm{~A}$ hospital based study in a tertiary care hospital of Bangladesh found the incidence of CHD was 25/1000 live births, that was higher in preterms as compared to full term. ${ }^{4}$

Growth retardation is a common health problem associated with congenital heart disease in children. Even children born with an appropriate birth weight for gestational age soon fall off their birth percentiles for weight and or/ height. ${ }^{5}$ Risk factors for poor growth in CHD are multifactorial and may include the increased metabolic demands of congestive heart failure, 
insufficient nutrient intake, the physiologic impact of the primary cardiac defect, and associated genetic and non cardiac disease. ${ }^{6}$ It is important to keep this in mind as at present most of the CHD can be corrected if diagnosed early and timely intervention is provided. This will result in normalization of their growth early due to decreased caloric requirement, better absorption, reduction in lower respiratory tract infections, etc. ${ }^{7}$ In developing country, prevalence of pre-operative growth delay in children with CHD was up to $45 \%{ }^{8}$ Infants with $\mathrm{CHD}$ and growth impairment typically show caloric deprivation and a reduction in adipose stores ${ }^{9}$. Anthropometric evaluations are very important for early identification of the patients with high risk for malnutrition. For this reason, it is necessary to measure at least weight and height of the newly hospitalized patients, and to calculate the required anthropometric values. ${ }^{10}$ The growth patterns of children with cyanotic and acyanotic congenital heart diseases are not well documented to us due to lack of adequate study. There are some studies in other countries but to the best of our knowledge, no such data about growth patterns of children with cyanotic and acyanotic congenital heart diseases are available in our country. This study was done to report and compare the growth patterns of patients with cyanotic and acyanotic congenital heart diseases.

\section{Materials and Methods:}

This comparative cross sectional study was done at department of Paediatrics, Sylhet M A G Osmani Medical College Hospital, (SOMCH), Sylhet during March 2014 to September 2014 on all patients with Echocardiographically proven cyanotic and acyanotic congenital heart disease aged 6 to 60 months, who admitted into Department of Paediatrics and satisfied the inclusion \& exclusion criteria. Children with any chronic illness (i.e. TB, malabsorption syndrome, etc.), children with other congenital anomalies, seriously ill child and unwillingness to participate in the study were excluded. Each patient interviewed after taking informed consent from the parents about the purpose of the study. Detailed history was taken meticulously by using structured questionnaire and was assessed thoroughly by using clinical variables. Chest X-ray and echocardiography were done. After enrollment, weight of each case was measured in empty stomach at morning by Beam scale, Hanging scale and Stadiometer according to the age, in metric system. If age of cases were $<2$ years, then length was measured by Infantometer and if age was $>2$ years, height was measured by Stadiometer in metric system. Then weight and length/height was plotted in WHO growth chart and growth pattern assessed by using $\mathrm{Z}$ score of weight for age, length/height for age and weight for length/ height and comparison of growth pattern between the children of cyanotic and acyanotic congenital heart disease was done. Collected data were checked and coded manually and analyzed using computer based software, SPSS version 21.

\section{Results:}

Mean age ( \pm standard deviation) of patients with cyanotic CHD was $28.88( \pm 15.12)$ and acyanotic CHD was $24.41( \pm 14.91)$ months. The p-value was 0.4823 , which was not significant in between groups. In cyanotic CHD, $66.67 \%$ patients were male and $33.33 \%$ patients were female whereas $53.33 \%$ patients of acyanotic CHD were male and $47.67 \%$ patients were female. The p-value was 0.2918, which was not significant in between the two groups. Most of the patients of cyanotic and acyanotic CHD belonged to middle class socioeconomic status with p value 0.5979 , which was also not significant in between the two groups (Table I).

Commonest type of cyanotic congenital heart disease was TOF (63.33\%) and then TGA (13.33\%) and TAPVC $(13.33 \%)$ (Table II). Commonest type of acyanotic congenital heart disease was VSD (53.33\%) and then PDA (20\%) (Table III). In cyanotic congenital heart disease $100 \%$ children had underweight. Among them, $23.33 \%$ had moderate and $76.67 \%$ had severe underweight. In acyanotic CHD, 93.33\% children had underweight, where $20 \%$ had moderate and $73.33 \%$ had severe underweight. The p-value was 0.35008 , which showed no significant differences in between the groups (Table IV). In cyanotic congenital heart disease, $96.66 \%$ children had stunting. Among them, $13.33 \%$ had moderate and $83.33 \%$ had severe stunting. In acyanotic congenital heart disease $43.33 \%$ children had stunting. Among them, 33.33\% had moderate and $10 \%$ had severe stunting. The p-value was $<0.0001$, which was highly significant in between the groups (Table V). In cyanotic congenital heart disease, $43.33 \%$ children had wasting. Among them, 30\% had moderate and $13.33 \%$ had severe wasting. In acyanotic CHD, $76.67 \%$ children had wasting, among them, $30 \%$ had moderate and $46.67 \%$ had severe wasting. The p-value was 0.0077 , which was highly significant in between the groups (Table VI). 


\section{Table-I}

\begin{tabular}{lccc} 
& \multicolumn{2}{c}{ Baseline characteristics } \\
Baseline characteristics & Cyanotic CHD & Acyanotic CHD & Significance(p value) \\
\hline Mean Age \pm SD & $28.88 \pm 15.12$ & $24.41 \pm 14.91$ & 0.4823 \\
Sex & 0.2918 & & \\
Male & $20(66.67 \%)$ & $16(53.33 \%)$ & \\
Female & $10(33.33 \%)$ & $14(47.67 \%)$ & \\
Socioeconomic status & 0.5979 & & \\
Poor & $12(40 \%)$ & $13(43.34 \%)$ & \\
Middle class & $18(60 \%)$ & $17(56.76 \%)$ & \\
\hline
\end{tabular}

*chi-square test was done

Table-II

\begin{tabular}{lcc}
\multicolumn{3}{c}{ Distribution according to type of Cyanotic CHD } \\
Type of Cyanotic CHD & Frequency & Percent \\
\hline TOF & 19 & 63.33 \\
TGA & 4 & 13.33 \\
TAPVC & 4 & 13.33 \\
TA & 3 & 10 \\
\hline Total & 30 & 100 \\
\hline
\end{tabular}

Table-III

\begin{tabular}{lcc}
\multicolumn{3}{c}{ Distribution according to type of Acyanotic CHD } \\
Type of Acyanotic CHD & Frequency & Percent \\
\hline VSD & 16 & 53.33 \\
PDA & 6 & 20 \\
ASD & 4 & 13.33 \\
TR & 1 & 3.33 \\
CoA & 1 & 3.33 \\
PS & 1 & 3.33 \\
AS & 1 & 3.33 \\
\hline Total & 30 & 100 \\
\hline
\end{tabular}

Table-IV

WAZ (Weight for age Z score) of CHD patients

WAZ

Cyanotic CHD

Acyanotic CHD

Significance

\begin{tabular}{lccccccc} 
& \multicolumn{2}{c}{$(\mathrm{n}=30)$} & & \multicolumn{2}{c}{$(\mathrm{n}=30)$} & ( $\mathrm{p}$ value) \\
\cline { 2 - 3 } & & Frequency & Percent & & Frequency & Percent & \\
\hline Well Nourished $\quad(+2$ to -2$)$ & 0 & 0 & & 2 & 6.67 & 0.35008 \\
Moderate Underweight $(-2$ to-3) & 7 & 23.33 & & 6 & 20 & \\
Severe Underweight $(<-3)$ & 23 & 76.67 & & 22 & 73.33 & \\
Total & 30 & 100 & & 30 & 100 & \\
\hline
\end{tabular}

*chi-square test was done 
Table-V

HAZ (Height/Length for age Z score) of CHD patients

\begin{tabular}{|c|c|c|c|c|c|}
\hline \multirow[t]{2}{*}{ HAZ } & \multicolumn{2}{|c|}{$\begin{array}{c}\text { Cyanotic CHD } \\
(\mathrm{n}=30)\end{array}$} & \multicolumn{2}{|c|}{$\begin{array}{c}\text { Acyanotic CHD } \\
(\mathrm{n}=30)\end{array}$} & \multirow[t]{2}{*}{$\begin{array}{l}\text { Significance } \\
\quad(\mathrm{p} \text { value })\end{array}$} \\
\hline & Frequency & Percent & Frequency & Percent & \\
\hline Well Nourished (+2 to -2$)$ & 1 & 3.33 & 17 & 56.67 & $<0.0001$ \\
\hline Moderate Stunting ( -2 to -3$)$ & 4 & 13.33 & 10 & 33.33 & \\
\hline Severe Stunting $(<-3)$ & 25 & 83.33 & 3 & 10 & \\
\hline Total & 30 & 100 & 30 & 100 & \\
\hline
\end{tabular}

*chi-square test was done

Table-VI

WHZ (Weight for Height/Length Z score) of CHD patients

\begin{tabular}{|c|c|c|c|c|c|}
\hline \multirow[t]{2}{*}{ Wasting (WHZ) } & \multicolumn{2}{|c|}{$\begin{array}{c}\text { Cyanotic CHD } \\
(n=30)\end{array}$} & \multicolumn{2}{|c|}{$\begin{array}{l}\text { Acyanotic CHD } \\
(n=30)\end{array}$} & \multirow[t]{2}{*}{$\begin{array}{c}\text { Significance } \\
\text { (p value) }\end{array}$} \\
\hline & Frequency & Percent & Frequency & Percent & \\
\hline Well nourished & $(+2$ to -2$) 17$ & 56.67 & 7 & 23.33 & 0.0077 \\
\hline Moderate wasting ( -2 to -3 ) & 9 & 30 & 9 & 30 & \\
\hline Severe wasting $(<-3)$ & 4 & 13.33 & 14 & 46.67 & \\
\hline Total & 30 & 100 & 30 & 100 & \\
\hline
\end{tabular}

*chi-square test was done

\section{Discussion:}

Most of the patients with cyanotic and acyanotic CHD belonged to 13-36 months age group. Hoque et al ${ }^{11}$ found in their study most of the CHD patient's age group was 29 days to 12 months. Varan et $\mathrm{al}^{7}$ found mean age of patients with cyanotic CHD was 17.9 months and 27.4 months in patients with acyanotic CHD. These finding are consistent with present study.

In the current study, $20(66.67 \%)$ patients of cyanotic CHD were male and $10(33.33 \%)$ patients were female and $16(53.33 \%)$ patients of acyanotic CHD were male; whereas 14 (47.67\%) patients were female. Overall male female ratio of CHD was 1.5:1. This finding was similar with Sharmin et al, ${ }^{4}$ Ibrahim et al, ${ }^{12}$ and Hoque et al, ${ }^{11}$ where male female ratio was $1.3: 1,1.2: 1$ and 1.7:1 respectively.

In the present study, the commonest type of cyanotic congenital heart disease was tetralogy of Fallot $(63.33 \%)$, on the other hand; ventricular septal defect
(53.33\%) was the commonest among acyanotic congenital heart disease. This correlated with studies of Hussain et al, ${ }^{13}$ Mollah et al ${ }^{14}$ and Hoque et al. ${ }^{11}$ But this differs from Rahman et al, ${ }^{15}$ and Begum et al. ${ }^{16}$ They found atrial septal defect as the commonest acyanotic lesion. This difference in observation might be due to including many adult patients by Rahman et $\mathrm{al}^{15}$ and only preterm babies by Begum et $\mathrm{al}^{16}$ in their studies.

In this study, $100 \%$ children with cyanotic congenital heart disease had underweight (Weight for age). Among them, $23.33 \%$ had moderate ( -2 to $-3 \mathrm{Z}$ ) and $76.67 \%$ had severe (<-3 Z) underweight. In acyanotic congenital heart disease, $93.33 \%$ children had underweight. Among them, 20\% had moderate and 73.33\% had severe underweight. These results showed no significant differences in between the two groups. Zaman et $\mathrm{al}^{17}$ showed $87 \%$ had underweight in cyanotic lesion, whereas $42.42 \%$ children had moderate and 
$18.18 \%$ children had severe underweight. In acyanotic lesion, they found in his study $89 \%$ children had underweight, among them $55.22 \%$ children had moderate and $23.88 \%$ children had severe underweight, which also showed no significant differences in between the two groups. This result correlated with the current study. Carrie et $\mathrm{al}^{6}$ also found results consistent with the present study. But Varan et $\mathrm{al}^{7}$ found $23 \%$ children with cyanotic congenital heart disease had underweight, among them, $13 \%$ had moderate and $10 \%$ had severe underweight. They found $31 \%$ children with acyanotic congenital heart disease had underweight, among them, 25\% had moderate and 6\% had severe underweight and there were no significant differences between cyanotic and acyanotic groups. But overall their study found fewer children had underweight which might be due to regional variation.

The current study showed, $96.67 \%$ children with cyanotic congenital heart disease had stunting (length/ height for age). Among them, $13.33 \%$ had moderate (2 to $-3 \mathrm{Z}$ ) and $83.33 \%$ had severe (<-3 Z) stunting. In acyanotic congenital heart disease, $43.33 \%$ children had stunting, whereas, $33.33 \%$ had moderate and $10 \%$ had severe stunting. This result showed highly significant difference in between the two groups, i.e., cyanotic group was significantly stunted than acyanotic group. These results were consistent with the study of Sjarif et a $1^{18}$ and Carrie et al. ${ }^{6}$ Sjarif et a ${ }^{18}$ found $90 \%$ children with cyanotic congenital heart disease had stunting. Among them, $54.5 \%$ had moderate and $36.4 \%$ had severe stunting. In acyanotic congenital heart disease, they found $79.4 \%$ children had stunting, whereas, $49.3 \%$ had moderate and $30.1 \%$ had severe stunting. But Zaman found $66.66 \%$ children had stunting in cyanotic lesion and $62.68 \%$ had stunting in acyanotic lesion. ${ }^{17}$ That study found, $30.3 \%$ children with cyanotic congenital heart disease had moderate stunting and $36.36 \%$ had severe stunting and in acyanotic congenital heart disease, $23.88 \%$ children had moderate stunting and $38.8 \%$ had severe stunting, which showed no significant difference in between cyanotic and acyanotic groups. ${ }^{17}$ The exact cause of stunting in cyanotic congenital heart disease is not well explained yet. This may be due to fact that chronic cyanosis causes chronic malnutrition.

The present study showed, $43.33 \%$ children with cyanotic congenital heart disease had wasting (Weight for length/height). Among them, 30\% had moderate (2 to $-3 \mathrm{Z})$ and $13.33 \%$ had severe (<-3 Z) wasting. Whereas, $76.67 \%$ children with acyanotic congenital heart disease had wasting. Among them, 30\% had moderate and $46.67 \%$ had severe wasting. This result showed highly significant difference in between two groups, i.e., acyanotic group was significantly wasted than cyanotic group. Sjarif et $\mathrm{al}^{18}$ and Carrie et $\mathrm{al}^{6}$ showed almost similar finding regard this. Sjarif et al ${ }^{18}$ found $63.6 \%$ children with cyanotic congenital heart disease had wasting. Among them, $40.9 \%$ had moderate and $22.7 \%$ had severe wasting. In acyanotic congenital heart disease, they found $76.4 \%$ children had wasting, whereas, $54.2 \%$ had moderate and $22.2 \%$ had severe wasting. But Zaman found $33.33 \%$ children had wasting in cyanotic lesion and $43 \%$ had wasting in acyanotic lesion. Where, $18.18 \%$ children with cyanotic congenital heart disease had moderate wasting and $15.15 \%$ had severe wasting and in acyanotic congenital heart disease, $20 \%$ children had moderate wasting and $23 \%$ had severe wasting, which showed no significant difference in between the two groups. ${ }^{17}$ The cuases of wasting in acyanotic congenital heart disease is also not clear. Some complications of acyanotic congenital heart diseases may cause acute malnutrition which may manifest as wasting.

\section{Conclusions:}

Growth failure was common in children with both cyanotic and acyanotic congenital heart disease. There was no significant difference in WAZ of patients with cyanotic and acyanotic CHD but stunting was significantly higher in patients with cyanotic CHD and wasting was significantly higher in patients with acyanotic CHD. Early recognition and intervention of growth failure can prevent the process of stunting of cyanotic CHD and wasting of acyanotic CHD.

\section{References:}

1. American Heart Association. Statistical Fact Sheet 2013. Update. Congenital Cardiovascular Defects. Available at: (www.heart.org), access on 2014 September 05.

2. Schoen FJ, Mitchell RN. The Heart. In: Cortan RS, Kumar V, Robins SL, editors. Robins and Cortans Pathologic Basis of Disease. $8^{\text {th }}$ ed. London: Saunders Elsevier; 2010. p.308-10.

3. Bernier PL, Stefanescu A, Samoukovic G, Tchervenkov CI. The challenge of congenital heart disease worldwide: epidemiologic and demographic facts. Semin Thorac Cardiovasc Surg Pediatr Card Surg Annu 2010;13:26-34. 
4. Sharmin LS, Haque MA, Bari MI, Ali MA. Pattern and Clinical Profile of Congenital Heart Disease in A Teaching Hospital. TAJ 2008; 21(2): 58-62.

5. Staebel OD. Malnutrition in Belgian Children with Congenital Heart Disease on admission to Hospital. J Clin Nurs 2000; 9: 784-91.

6. Carrie D, Ashley N, Aaron P, Meryl S. Growth in Children with Congenital Heart Disease. Pediatrics 2013; 131(1): 236-42.

7. Varan B, Tokel K, Yilmaz G. Malnutrition and growth failure in cyanotic and acyanotic congenital heart disease with and without pulmonary hypertension. Arch Dis Child 1999; 81 (1): 49-52.

8. Vaidyanathan B, Roth SJ, Rao SG, Gauvreau K, hivaprakashi K, Kumar RK. Outcome of ventricular septal defect repair in a developing country. J Pediatr 2002; 140: 736-41.

9. Krieger I. Growth Failure and Congenital Heart Disease. Energy and Nitrogen balance in Infants. Am J Dis Child. 1970;120(6): 497-502.

10. Ferreira HS, Franca AOS. Evolution of nutritional status in hospitalized children. Journal de Pediatra 2002; 78:491-6.

11. Hoque M, Hussain MM, Ahmed ATR, Uddin MS. Pattern of Congenital Heart Disease in Children Admitted into Tertiary Care Hospitals of Sylhet : A Multicenter Study. Bangladesh J Child Health 2014; 38 (1): 15-8.
12. Ibrahim SA, Abdelrahman $\mathrm{MH}$, ElshazaliOH. Pattern and Diagnosis of Congenital Heart Disease in Patients attending Ahmed Gasim Cardiac Centre. Sudan JMS.2012;7(4):249-54.

13. Hussain M, Hossain M, Amin SK, Molla MR. Pattern of congenital heart disease in Dhaka Shishu Hospital. D S (Child) H J 1992; 8:35-46.

14. Mollah MAH, Begum NA, Islam MN, Mahmud RS, Haq MA, Nahar N, Rashid MA. Clinical profile of congenital heart disease (CHD): An Analysis of 218 Cases. Bangladesh heart J 2002; 17 : 62-7.

15. Rahman S, Ahmed MN, Rahmatullah KHI, Alam MS. The Incidence of Congenital Heart Diseases Diagnosed by NonInvasive Technique- Ten Years Study in Bangladesh. D S (Child) H J 1992; 8: 5-15.

16. Begum NNF, Ahmed QS. Pattern of Heart disease among neonates and their outcome: one year experience in non-invasive cardiac laboratory of Combined Military Hospital, Dhaka. Bangladesh J child health 2001; 25: 48-52.

17. Zaman WM. A study on nutritional status of children with congenital heart disease using anthropometric measurement [Dissertation]. Dhaka: BCPS; 2011.

18. Sjarif SL, Damayanti R, Anggriawan ST, Putra MM. Anthropometric profiles of children with congenital heart disease. Med J Indones 2011; 20:40-5. 